\title{
AGE PECULIARITIES OF MORPHOLOGICAL CHANGES OF VESSELS OF TESTICULAR HEMOMICROCIRCULATORY FLOW IN STREPTOZOTOCIN DIABETES MELLITUS
}

\author{
Ivan-Andriy Kondrat
}

\author{
Ivano-Frankivsk National Medical University, Ukraine
}

\begin{abstract}
Medico-social problem of diabetes is caused by early disability and mortality of patients due to specific complications of micro- and macroangiopathies.

Therefore, the aim of our study was to establish morphological changes in vessels of the hemomicrocirculatory flow of the testes of immature rats with experimental streptozotocin diabetes mellitus (SDM).

Materials and methods. The material for the study were the testicles of 20 two-month-old immature (weighing 65-95 g) white outbred male rats, which were divided equally into 2 groups: experimental and control ones. SDM in animals of the experimental group was simulated by a single intraperitoneal injection of streptozotocin (dissolved in $0.1 \mathrm{M}$ citrate buffer solution with a $\mathrm{pH}$ of 4.5 ) at a dose of $7 \mathrm{mg}$ per $100 \mathrm{~g}$ of mass. The control group of animals received intraperitoneally an equivalent dose of $0.1 \mathrm{M}$ citrate buffer. Histological, electron microscopic, biochemical, morphometric and statistical research methods were used.

Results. It was found that in the early stages of SDM (14 $4^{\text {th }}$ day) on the background of hyperglycemia in the hemomicrocirculatory flow of the testes there is a spasm of the vessels of the afferent link, which is confirmed by a decrease in the area of arterioles lumen and an increase in their VI.

On the $56^{\text {th }}$ day of SDM, on the background of elevated levels of glucose and glycosylated hemoglobin in the links of the hemorrhagic circulatory flow of the testes there are initial signs of diabetic microangiopathy, manifested by: hemorheological disorders in micro-hemovessels (erythrocyte sludges, adhesion of erythrocytes and platelets, microclasmatosis), decreased capacity of arterioles and capillaries (increase in VI, respectively by 1.2 and 1.9 times), microclasmatosis, thickening and proliferation of the basement membrane of capillaries.

Conclusion. On the $56^{\text {th }}$ day of SDM in the hemomicrocirculatory flow of the testes, the development of diabetic microangiopathy is observed, which leads to the disruption of the blood-testis barrier, and as a consequence, to a violation of spermatogenesis.
\end{abstract}

Key words: testis, hemomicrocirculatory flow, streptozotocin diabetes mellitus.

Problem statement and analysis of recent research. The number of patients with diabetes mellitus (DM) is increasing exponentially every year, and this encourages scientists to improve existing methods and search for new technique of treatment and diagnosis of this pathology. In Ukraine, an annual increase in the number of patients with DM is registered by an average of 5-7\%, and among children under 17 years of age this figure is $3.4 \%-6 \%$ [ 4 , 19]. However, the real number of patients in Ukraine, as shown by the results of epidemiological studies, is 2-2.5 times higher because of undiagnosed cases of the disease [15]. Due to the high prevalence and increase in the number of patients, DM is classified as a social ailment, as it is a part of a triad of diseases along with cancer and cardiovascular disorders, which are the leading causes of disability and death among people [9, 20]. The most lifethreatening complication of diabetes is vascular damage, which develops in $80-100 \%$ of patients $[2,11]$. According to WHO statistics, mortality from vascular complications has increased from $21.2 \%$ to $77 \%$ over the past 90 years [17]. Medico-social problem of DM is caused by early disability and mortality of patients due to specific complications, such as microangiopathy (nephropathy, retinopathy), macroangiopathy (myocardial infarction, stroke, gangrene of the lower extremities), neuropathy, as well as sexual dysfunction [1, 7]. Hyperglycemia leads to oxidative stress and the formation of reactive oxygen species, which can cause decreased testosterone levels, changes in the structure of the seminal tubules, impaired spermatogenesis which can lead to male infertility $[10,18]$.

In view of the above, the aim of our study was to establish morphological changes in the vessels of the hemomicrocirculatory flow of the testes of immature rats with experimental streptozotocin diabetes mellitus (SDM).

\section{Materials and methods}

The material for the study were the testes of 20 two- month-old immature (weighing 65-95 g) white outbred male rats, which were divided into 2 groups: experimental and control ones. SDM in animals of the experimental group was simulated by a single intraperitoneal injection of streptozotocin (dissolved in $0.1 \mathrm{M}$ citrate buffer solution with a $\mathrm{pH}$ of 4.5 ) at a dose of $7 \mathrm{mg}$ per $100 \mathrm{~g}$ of mass. $0.1 \mathrm{M}$ citrate buffer in an equivalent dose was injected intraperitoneally to the control group of animals. Glucose levels in the experimental group of animals were determined daily from a drop of tail vein blood using test strips on "Accu-Chec" glucometer (Germany). To monitor the course of the SDM in the vivarium, a portable glucometer "Accu-Chek Active" (Roche Diagn, GH, Germany") with a standard set of test strips was used. The content of HbAlc in the blood was determined in a certified laboratory "Diameb". The material was taken on the 14th and 56 th days of the experiment.

All manipulations performed on animals during the experiment did not contradict the provisions of the European Convention for the Protection of Vertebrate Animals Used for Research and Other Scientific Purposes (Strasbourg, 1986), Council of Europe Directive 86/609/EEC (1986), Law of Ukraine "On protection of animals from cruel treatment" of December 15, 2009 and orders of the Ministry of Health of Ukraine No.690 of September 23, 2009, No.616 of August 3, 2012.

Histological (hematoxylin-eosin staining, Masson's trichrome) and electron microscopic methods were applied. For morphometric studies, histological sections were used (the field of view of the Leica DM750 light microscope was photographed using a ToupCam 5.2M UHCCD C-Mount Sony digital camera). Morphometry was performed using ImageJ version 1.47t. The area of the profile field of arterioles, capillaries, venules, their walls and lumen was measured. In arterioles and capillaries, the Vaughanworth index (VI) was determined by the formula [16]: $\mathrm{W}=\mathrm{S}_{0} / \mathrm{S}_{\text {lum }}$ $x 100$, where $S_{o}$ is the vessel wall area $\left(\mu m^{2}\right) ; S_{\text {lum }}$ - the area of the vessel lumen $\left(\mu \mathrm{m}^{2}\right)$. Statistical analysis was performed 
using the statistical package Stat.Soft.Inc; Tulsa, OK, USA; Statistica 10.

\section{Results of the research}

On the $14^{\text {th }}$ day of the development of SDM, in the blood of two-month-old rats, a probable increase in glucose and HbA1c levels to $13.68 \pm 0.58 \mathrm{mmol} / \mathrm{l}$ (control $-3.49 \pm 0.24$ $\mathrm{mmol} / \mathrm{l}, \mathrm{p}=0.0026)$ and $7.17 \pm 0.48 \%$ (control $-2.03 \pm 0.19 \%$, $\mathrm{p}=0.0013$ ) were observed. Such biochemical changes indicate the development of a subcompensated form of diabetes.

On the $14^{\text {th }}$ day of the development of SDM in the hemomicrocirculatory flow of the testes, spasm of most arterioles was observed, while the metabolic and capacitive vessels at the optical level didn't have pronounced changes (Fig. 1b). The inner elastic membrane of arterioles on histological preparations of rats with SDM looks like a dark, somewhere broken up thickened spiral, whereas in the control group of animals it is clearly visible around the perimeter of the vessels. Qualitative data of histological examinations are confirmed by morphometry data. Thus, the area of arterioles probably decreases to $454.95 \pm 106.02$ $\mu \mathrm{m}^{2}$ (control $-554.18 \pm 31.48 \mu \mathrm{m}^{2}, \mathrm{p}=0.0419$ ) due to the reduction of the area of their lumen to $63.61 \pm 19.59 \mu^{2}$ (control $-128.64 \pm 11.32 \mu \mathrm{m}^{2}, \mathrm{p}=0.0009$ ), while the wall area probably does not change and is $391.34 \pm 89.03 \mu \mathrm{m}^{2}$ (control - 425.54 $\left.\pm 33.91 \mu \mathrm{m}^{2}, \mathrm{p}=0.5635\right)$. This morphometric rearrangement of arterioles leads to an increase in VI to $729.50 \pm 90.06 \% \quad$ (control $-334.57 \pm 50.20 \%, \quad \mathrm{p}=0.0009)$ and indicates a decrease in their capacity. According to morphometric studies and statistical analysis, the probable quantitative changes in the capillaries and venules of rats with SDM, compared with the control group of animals, were not detected. Thus, the area of capillaries and venules was $48.07 \pm 4.86 \mu \mathrm{m}^{2}$ (control $-49.06 \pm 3.91 \mu \mathrm{m}^{2}, \mathrm{p}=0.9162$ ) and $729.19 \pm 51.03 \mu \mathrm{m}^{2}$ (control $\left.-741.14 \pm 58.96 \mu \mathrm{m}^{2}, \mathrm{p}=0.5982\right)$, the area of their lumen was $12.92 \pm 0.51 \mu^{2}$ (control $12.01 \pm 0.42 \mu \mathrm{m}^{2}, \mathrm{p}=0.5251$ ) and $497.71 \pm 23.75 \mu \mathrm{m}^{2}$ (control $\left.-509.64 \pm 36.91 \mu \mathrm{m}^{2}, \mathrm{p}=0.5251\right)$, wall area $-35.14 \pm 4.88 \mu \mathrm{m}^{2}$ (control $-36.16 \pm 3.92 \mu \mathrm{m}^{2}, \mathrm{p}=0.9162$ ) and $231.48 \pm 58.72$ $\mu \mathrm{m}^{2}$ (control $-231.50 \pm 57.01 \mu \mathrm{m}^{2}, \mathrm{p}=0.8336$ ). Most venous vessels are filled with cellular elements of blood.

At the ultrastructural level, the lumen of some arterioles acquires a slit-like shape due to a spasm. The cytoplasm of smooth myocytes contains a large number of expanded tanks of the granular endoplasmic reticulum with a few fixed ribosomes on it. In the mitochondria of endothelial cells and myocytes, the matrix is illuminated and the cristae are
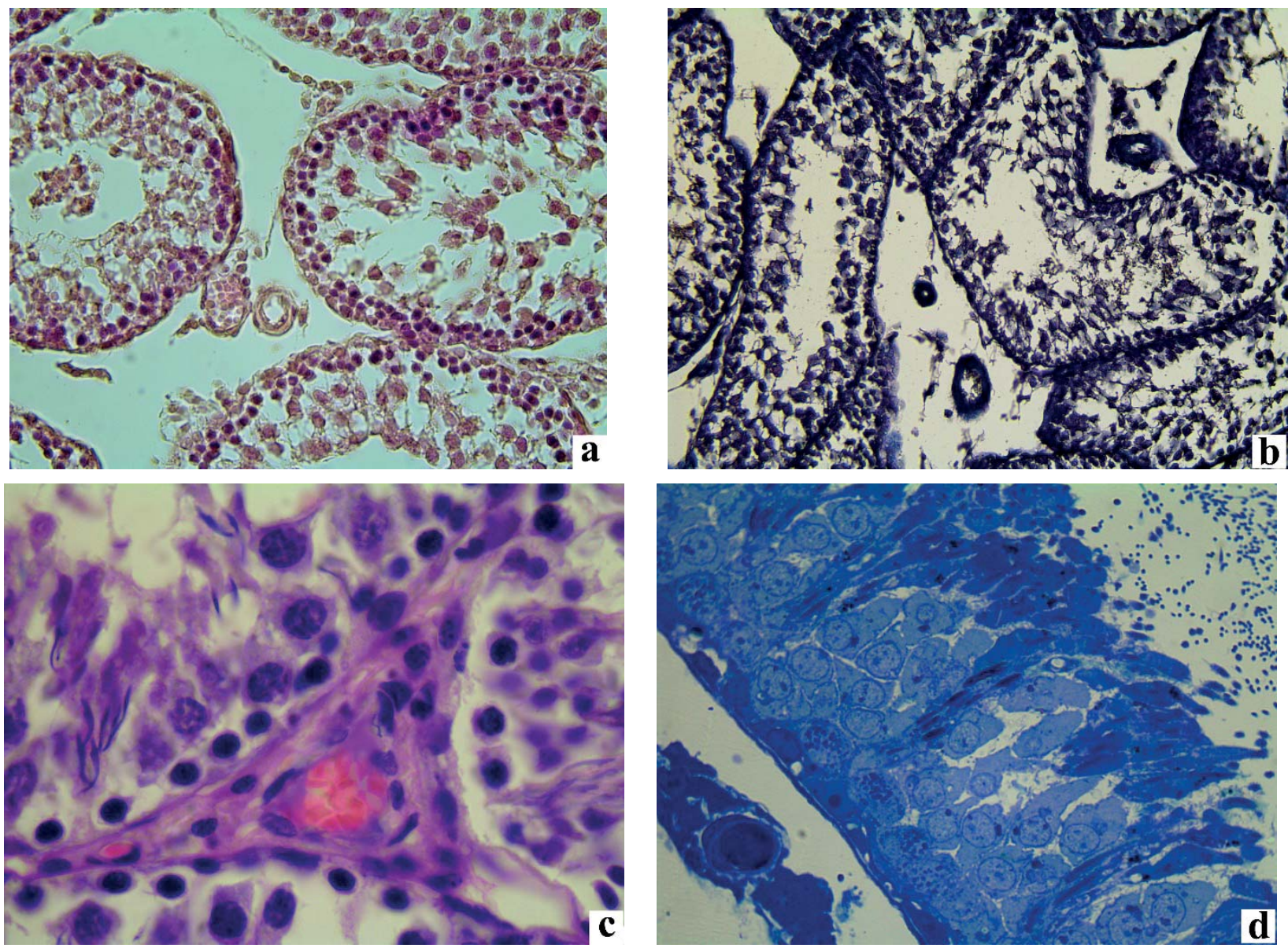

Fig.1. Morphological changes in vessels of the hemomicrocirculatory flow of the testes of rats of control group (a) and with experimental diabetes mellitus (b-d). Spasm of arterioles on the $14^{\text {th }}$ day of streptozotocin diabetes (b). Erythrocyte sludges in the venules (c) and capillaries (d) of the testes on the $56^{\text {th }}$ day of experimental diabetes mellitus. Microphotographs. Staining: hematoxylin-eosin (a, c), Masson's trichrome (b), semifine sections stained with methylene blue (d).

Enl.: a, b, c) x400, d) x1000. 
disorganized. The nuclei of endothelial cells have an oval shape and diffusely scattered granules of euchromatin, and their membrane forms a few shallow invaginations. The basement membrane is clearly visualized along the entire outer perimeter of endothelial cells and smooth myocytes.

At the ultrastructural level, reactive changes are noted in most capillaries: the nuclei of edotheliocytes acquire different shape due to invagination of the nuclear membrane. In some capillaries, the nucleus-containing zone protrudes sharply into the lumen of the vessel, due to which the latter acquires a slit-like shape. In capillary endotheliocytes there is an increased number of pinocytic vesicles along the inner surface of the lumenal and basal plasmalemmas, which may indicate an increase in transendothelial metabolism.

The ultrastructural construction of the venous link of the hemomicrocirculatory flow in this observation period remains the same as in control animals, except for pronounced erythrocyte sludges in the lumen of blood vessels, adhesion of individual erythrocytes to the lumenal plasmalemma of endothelial cells.

On the $56^{\text {th }}$ day after modeling the SDM, the glucose level increases to $16.01 \pm 0.32 \mathrm{mmol} / \mathrm{l}$ (control - 3.56 \pm 0.43 $\mathrm{mmol} / \mathrm{l}, \mathrm{p}=0.0001$ ), $\mathrm{HbA}_{1 \mathrm{c}}$ - up to $9.56 \pm 0.21 \%$ (control $(2.34 \pm 0.17) \%, \mathrm{p}=0.0001)$, which indicates the development of decompensated SDM. These values significantly increase compared to the previous observation period (in all cases $\mathrm{p}<0.05)$.

On the 56th day of the SDM, in the vessels of the hemomicrocirculatory flow, the dystrophic-destructive changes increase against the background of severe hemorheological disorders (erythrocyte sludge, adhesion of platelets and erythrocytes to the wall of endothelial cells). In arterioles, the inner elastic membrane loses its tortuosity and acquires uneven thickness due to its plasma permeation. The lumens of capillaries and venules are filled with erythrocyte sludges (Fig. $1 \mathrm{c}-\mathrm{d}$ ).

According to morphometric analysis on the $56^{\text {th }}$ day, the areas of arterioles and their lumen are smaller than the control values and are respectively $671.43 \pm 50.67 \mu^{2}$ (control - 772.05 $\left.\pm 94.51 \mu^{2}, p=0.0313\right)$ and $127.85 \pm 11.83 \mu^{2}$ (control $-166.76 \pm 19.12 \mu \mathrm{m}^{2}, \mathrm{p}=0.5635$ ), while the area of their wall probably does not change, compared to the control values and is $543.58 \pm 55.34 \mu^{2}$ (control - 605.29 \pm 79.92 $\mu \mathrm{m}^{2}, \mathrm{p}=0.1036$ ). The above values are likely to increase, compared to the previous observation period (in all cases $\mathrm{p}<0.05)$. VI in arterioles probably decreases, compared to the previous term of the experiment to $430.28 \pm 72.91 \%$ $(p=0.0009)$, but remains higher than the control values (control $-634.16 \pm 35.16 \%, \mathrm{p}=0.0406$ ). Such morphometric rearrangement of arterioles indicates partial compensation of hemomicrocirculation and restoration of their capacity.

In the testes at this time during the SDM, the area of capillaries and their lumen is probably reduced, compared with the control values $62.83 \pm 6.88 \mu \mathrm{m}^{2}$ (control $-72.28 \pm 4.82$ $\mu \mathrm{m}^{2}, \mathrm{p}=0.0136$ ) and $15.55 \pm 1.92 \mu \mathrm{m}^{2}$ (control - 28.22 \pm 2.99 $\mu \mathrm{m}^{2}, \mathrm{p}=0.0009$ ), while their wall area probably does not change and is $47.29 \pm 5.63 \mu \mathrm{m}^{2}$ (control - 44.06 $\pm 2.44 \mu \mathrm{m}^{2}$, $\mathrm{p}=0.1562$ ), which leads to an increase in VI to $305.90 \pm 32.89$

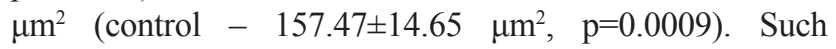
morphometric changes of capillaries, in comparison with the previous term of experiment, indicate decrease in their capacity.

On the $56^{\text {th }}$ day of the SDM, there were no probable changes in the morphometric analysis of the capacitive link of the hemomicrocirculatory flow, compared with the control values. Thus, the area of venules is $853.78 \pm 61.25$ $\mu \mathrm{m}^{2}$ (control $-830.71 \pm 89.24 \mu \mathrm{m}^{2}, \mathrm{p}=0.5995$ ), the area of their lumen - 531.35 $\pm 79.34 \mu^{2}$ (control - 527.35 \pm 78.53 $\mu \mathrm{m}^{2}, \mathrm{p}=0.9856$ ), wall area $-322.43 \pm 53.76 \mu \mathrm{m}^{2}$ (control $303.36 \pm 60.34 \mu \mathrm{m}^{2}, \mathrm{p}=0.4622$ ). It should be noted that the area of the venule and its wall is likely to increase, compared with the previous observation period (in all cases $\mathrm{p}<0.05$ ).

In the ultrastructural examination of blood microvessels, special attention should be paid to erythrocyte sludges in the form of coin columns, adhesion of erythrocytes and platelets to the lumenal surface of endothelial cells, and sometimes microthrombi in the lumen of the venules. The cytoplasm of most endotheliocytes of arterioles and capillaries is electrondense (Fig. 2). In the cytoplasm of endothelial cells small and large vacuoles, single pinocytic vesicles and multivesicular bodies are found. The lumenal surface of endothelial cells has uneven contours and forms bulges and invaginations of different size into the lumen of the microvessel, often ending in microclasmatosis. In some endotheliocytes karyopyknosis is noted, in others - karyolysis, and in some of them the karyoplasm has moderate electron density. A heterogeneous population of mitochondria is characteristic. In some of them there is an enlightenment of a matrix and fragmentation of crystals, and in others - diffuse homogenization.

Arteriole myocytes have an elongated shape with high electron density and contain medium-sized vacuoles. In the cytoplasm of these cells, the membrane organelles are partially destroyed, there are small vacuoles. The inner elastic membrane loses its tortuosity, is thick in some places and has different osmophilicity.

The basement membrane of capillaries is considerably thickened (Fig. 2a), and cytoplasmic processes of pericytes are located in its stratifications. In some capillaries there is a proliferation of the basement membrane in the form of individual plates, which is one of the markers of diabetic capillaropathy. In the latter, karyopyknosis, expansion of granular endoplasmic reticulum tanks, destructuring and partial lysis of mitochondrial cristae are noted. Pericapillary spaces are expanded due to plasma permeation and filled with collagen fibers, active fibroblasts, mast cells at different stages of degranulation. In general, such changes in the capillaries in the pericapillary spaces with the thickening of the basement membrane of the convoluted seminal tubules indicate an impairment of the hematotesticular barrier.

Endothelial cells undergo destructive changes in venules by type of vacuolar dystrophy (Fig. 2 b). Their wall is thickened due to plasma impregnation and growth of loose connective tissue.

\section{Discussion}

On the $14^{\text {th }}$ day of the development of SDM, a decrease in the capacity of the afferent link of the hemomicrocirculatory flow due to spasm of the arterioles (reduction of their lumen by $50.6 \%$ ) and an increase in their VI by 2.2 times were observed. Such changes are due to several pathogenetic mechanisms. Most authors point to increased activity of aldosterone-renin-angiotensin system and high levels of 

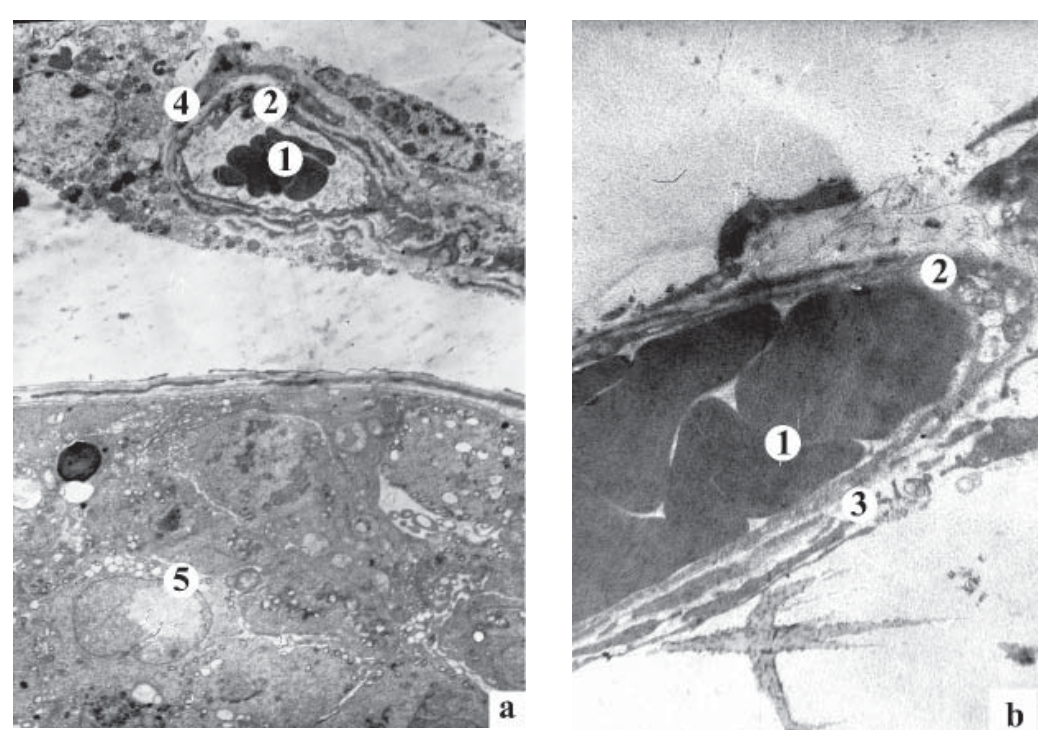

Fig. 2. Erythrocyte sludges and microclasmatosis in the vessels of the hemomicrocirculatory flow of the testes on the $56^{\text {th }}$ day of streptozotocin diabetes mellitus. Electronic microphotographs. Enl.: a) x1600; b) x4800.

Designations: 1 - erythrocyte sludges, 2 - endotheliocyte, 3 - basement membrane, 4 - pericyte, 5 - spermatogenic epithelium.

to cell membranes. An important factor in endothelial damage in diabetes is the sorbitol pathway of glucose metabolism, which is associated with the activation of aldoreductase with subsequent accumulation of sorbitol in endothelial cells, leading to osmotic edema and destruction of the latter $[2,5]$.

According to our studies, on the $56^{\text {th }}$ day of the SDM, the lumenal surface of endothelial cells of arterioles and capillaries forms numerous microprocesses, folds, microvilli with the subsequent development of microclasmatosis. Such changes in the lumenal surface of endothelial cells are interpreted differently by researchers. Some authors attribute this to the capture of material from the lumen of blood vessels [14], others - with reactive changes in the endothelium due to changes in blood flow [8]. Hyperglycemia due to increased activity of glucosyltransferase $[2,5]$ causes increased synthesis of glycoproteins in the basement membrane, which, according to

catecholamines in diabetes, which cause vasoconstriction and increase blood thrombogenic activity, contributing to impaired microcirculation $[3,21]$. Increased secretion of glucocorticoids in the blood of mice with streptozotocin DM has been indicated by other authors [13] and they associate it with changes in the hippocampus. Other authors [12] associate high corticosterone levels in mice with streptozotocin diabetes with hypersensitivity of adrenal cortex cell culture to ACTH, which is significantly increased in the paraventricular nucleus of the hypothalamus and hippocampus. Gohshi A. et al. [6] indicate high levels of ACTH in the early stages of streptozotocin diabetes and associate it with high levels of corticoliberin.

Increasedactivityofthepituitary-adrenalsysteminratswith SDM with hyperproduction of ACTH and hypercortisolemia, leads to a further increase in the symptoms of diabetes, in particular the development of microangiopathies [21]. Thus, according to our studies, on the $56^{\text {th }}$ day of SDM in the vessels of the hemomicrocirculatory flow there are initial signs of the development of microangiopathy (erythrocyte sludges, adhesion of erythrocytes and platelets to endothelial cells), which are a response to hyperglycemia and high levels of glycosylated hemoglobin $(9.56 \pm 0.21 \%)$. It is believed that the initiating factor of endothelial dysfunction in diabetes is the process of "glucosizing" of the hemoglobin, as a result of which erythrocytes change their surface S-charge. This leads to true capillary stasis, sludge and agglutination of erythrocytes, and later - to microthrombosis, which creates local circulatory and hemic hypoxia and activates a cascade of molecular mechanisms of cell membrane damage $[2,5]$. Additional factors of endothelial cell membrane damage are considered to be ketoacidosis and "glucosizing" of the $\mathrm{N}$-terminus of transmembrane proteins, which leads to a decrease in their synthesis of vasodilators (nitric oxide and prostacyclins). The resulting spasm of the arterioles exacerbates hypoxia and, accordingly, free radical damage our studies, leads to its thickening and hyalinosis.

\section{Conclusions}

In the early stages of SDM (14 ${ }^{\text {th }}$ day) on the background of hyperglycemia in the hemomicrocirculatory flow of the testes, there is a spasm of the vessels of the afferent link, which is confirmed by a decrease in the lumen of the arterioles and an increase in their VI.

On the $56^{\text {th }}$ day of SDM, on the background of elevated levels of glucose and glycosylated hemoglobin in the links of the hemomicrocirculatory flow of the testis, there are initial signs of diabetic microangiopathy manifested by: hemorheological disorders in microhemovessels (erythrocyte sludge, adhesion of erythrocytes and platelets, microclasmatosis), decreased capacity of arterioles and capillaries (increase in VI in them, respectively by 1.2 and 1.9 times), microclasmatosis, thickening and proliferation of the basement membrane of capillaries.

\section{Prospects for further research}

The study of morpho-functional changes in the convoluted seminal tubules of two-month-old rats with SDM is promising for supplementing the existing information on the pathogenetic mechanisms of male infertility in this pathology and the role of diabetic microangiopathy. The obtained data on changes in the microcirculatory system of the testes in SDM can serve as a theoretical basis for improvement of existing techniques and development of new methods of treatment of diabetic microangiopathy and testopathy.

Financial Disclosure. The authors declared no financial support.

Conflict of Interest. The authors stated no conflict of interest. 


\section{References}

1. Alves M, Martins A, Rato L, Moreira P, Socorro S, Oliveira P. Molecular mechanisms beyond glucose transport in diabetesrelated male infertility. Biochim. Biophys. Acta. 2013;1832:626635.

2. Borovkova O, Iftodii A. Problem of pathogenesis of diabetic angiopathies. Bukovynian Medical Bulletin. 2006;10(2):132-135.

3. Cherkasova OP, Kuznetsova NV, Palchikova NA Soliatitskaia VG. The activity of the adrenocortical system in experimental diabetes in rats. Diabetes Mellitus. 2011;2:37-40.

4. Chudhary D, Cleveland DA, Agdere L, Graetz R, Etienne D. Does the Use of Diabetes Electronic Medical Record Template Lead to Improvement of Screening for Complications of Tipe 1 Diabetes Mellitus in the Pediatric Population. Pediatrics. 2018;141(1):122128.

5. Efimov A, Zueva N, Skrobonskaia N. Diabetic angiopathies: etiology and pathogenesis. Drugs. 2004; 11:36-38. Russian.

6. Gohshi A, Honda K, Tominaga K, Takano Y, Motoya T, Yamada $\mathrm{K}$ et al. Changes in adrenocorticotropic hormone (ACTH) release from the cultured anterior pituitary cells of streptozotocininduced diabetic rats. Biol Pharm Bull. 1998; 21(8):795-799.

7. Khan MA, Katta M, Gurunadh VS, Moulick PS, Gupta S, Sati A. A clinical correlation of conjunctival microangiopathy with grades of retinopathy in type 2 diabetes mellitus. Med. J. Armed Forces India. 2017;73(3):261-266. https://doi.org/10.1016/j. mjafi.2017.01.005. Epub 2017 Feb 16.

8. Kuryliszyn-Moskal A, Zarzycki W, Dubicki A, Moskal D, KosztyE, Hojna B et al. Clinical usefulness of videocapillaroscopy and selected endothelial cell activation markers in people with Type 1 diabetes mellitus complicated by microangiopathy. Adv Med Sci. 2017;62(2):368-373.

9. Li Y, Zeng KW, Wang XM. Cerebral microangiopathy of diabetes. Zhongguo Zhong Yao Za Zhi. 2017;42(12):2247-2253.

10. Mohasseb M, Ebied S, Yehia M.A and Hussein $\mathrm{N}$.:Testicular oxidative damage and role of combined antioxidant supplementation in experimental diabetic rats. Journal of Physiology and Biochemistry. 2011;67:185-194.

11. Ponto KA, Koenig J, Peto T, Lamparter J, Raum P, Wild PS, et al. Prevalence of diabetic retinopathy in screening-detected diabetes mellitus: results from the Gutenberg Health Study (GHS). Diabetologia. 2016;59(9):191-193.

12. Revsin Y, D van Wijk, Saravia FE. Adrenal hypersensitivity precedes chronic hypercorticism in streptozotocin-induced diabetes mice. Endocrinology. 2008;149(7):3531-3539.

13. Revsin Y, Rekers NV, Louwe MC, Saravia FE, De Nicola AF, de Kloet ER et al. Glucocorticoid receptor blockade normalizes hippocampal alterations and cognitive impairment in streptozotocininduced type 1 diabetes mice. Neuropsychopharmacology. 2009;34(3):747-758.

14. Roustit M, Loader J, Deusenbery C, Baltzis D, Veves A. Endothelial Dysfunction as a Link Between Cardiovascular Risk Factors and Peripheral Neuropathy in Diabetes. J Clin Endocrinol Metab. 2016;101(9):34018.

15. Savytskyi IV, Sarakhan VM, Kuzmenko IYa, Yakymchuk NV. Experimental study of diabetes mellitus: features of modeling techniques. Ukrainian Journal of Medicine, Biology and Sports. 2017;6(8):41-45.

16. Shavrin VA, Avramenko YuN. Comparative morphometry of cerebral microvessels in atherosclerotic and diabetic encephalopathy. Morphologia. 2017;11(1):58-61. Russian.

17. Tomita M, Kabeya Y, Okisugi M, Katsuki T, Oikawa Y, Atsumi Y, et al. Diabetic Microangiopathy Is an Independent Predictor of Incident Diabetic Foot Ulcer. J. Diabetes Res. 2016; 2016: 5938540. https://doi.org/10.1155/2016/5938540

18. Yang X, Huo F, Liu B, Liu J, Chen T, Li J, Zhu Z, Lv B. Crocin Inhibits Oxidative Stress and Pro-inflammatory Response of Microglial Cells Associated with Diabetic Retinopathy Through the Activation of PI3K/Akt Signaling Pathway. J Mol Neurosci. 2017;61(4):581-589. https://doi.org/10.1007/s12031-017-0899-8.

19. Zelinska NB. Statistics of diabetes mellitus among children in Ukraine (analysis and forecast). Ukrainian Journal of Pediatric Endocrinology. 2015;3(4):8-14.

20. Zhurakivska OYa, Mykulets TI, Dutchak UM, Klypych YaI, Miskiv VA, Hrechyn AB, Klypych OO. Structural changes of endocrine system of myocardium during the streptozotocin diabetes mellitus. World of medicine and biology. 2018;1(63):126-130.

21. Zhurakivska OYa, Zhurakivskyi VM, Miskiv VA, Dutchak UM, Kulynych HB, Tkachuk YuL. Morphofunctional changes of adrenal glands in early stages of streptozotocin diabetes mellitus. Clinical Anatomy and Operative Surgery. 2019;2(18):82-88.

Received: 19.05 .2021

Revised: 23.05.2021

Accepted: 24.05.2021 